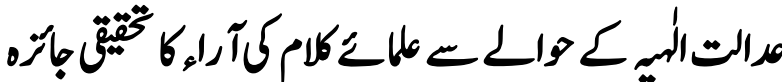

\section{A Scholarly Analysis of Adl'ilähi - the Divine Justice- in the Light of The Opinions of Muslim Theologians}

\author{
Dr. Sayyed Hasan Askārī Naqvī \\ Vice Principal, IMCB, Islāmbād, Pakistān
}

Dr. Shazia Hasan

Assistant Professor, National Defence University, Islāmbād, Pakistān

\begin{abstract}
:
This essay discusses the topic of Justice of God ('Adl'ilāhī) with reference to the issue of free will and predestination and the position of the various schools of Islamic theology regarding it. The opinion of the Mü'tazilä, who believed in complete free will of man, stood opposed to that of the Ashä'ira who considered the actions of men to be predetermined by Divine ordainment. The Imāmia' $h$, on the other hand, believed in a position between these two extremes. The study further discusses the difference amongst the theologians in identifying goodness of a good deed with itself, and the evil of an evil act as inherent within it. This was the position of the Mü'tazilā and the Imāmīa'h whereas the Ashä'irā believed that it was the shäri'ah that granted the goodness or evilness to any act. Finally, the apparent contradiction between the Justice of God and the presence of evil in this world is addressed and reconciled.
\end{abstract}

Keywords: 'Adl'ilāhī, Mū'tazilā, Ashā'irā, Jafār Sadiq, Qur'ān

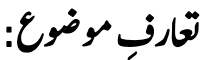

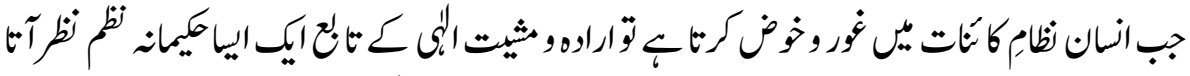

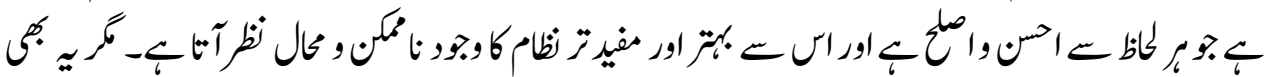

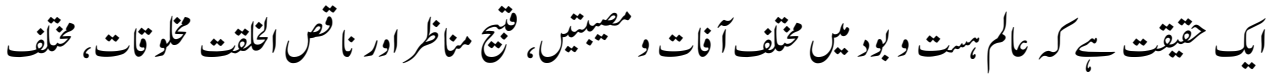

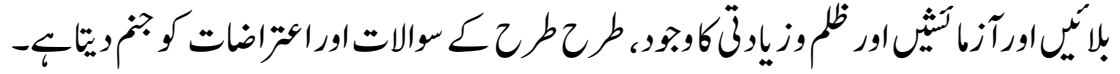

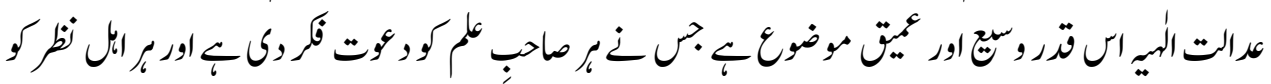

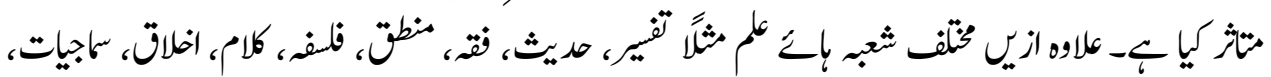

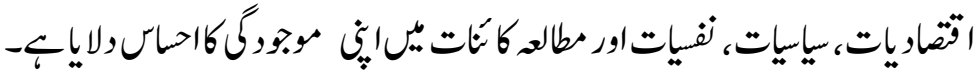




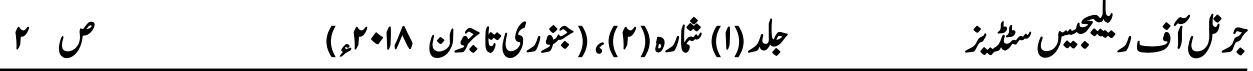

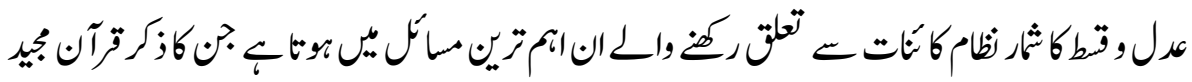

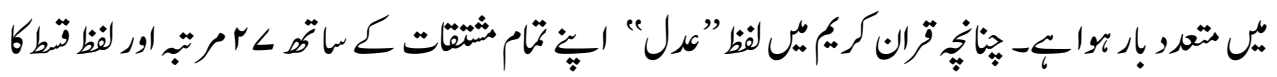

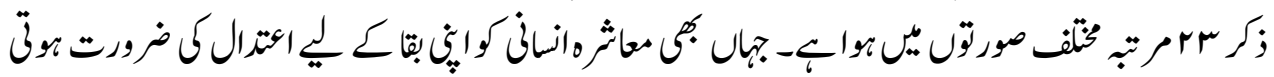

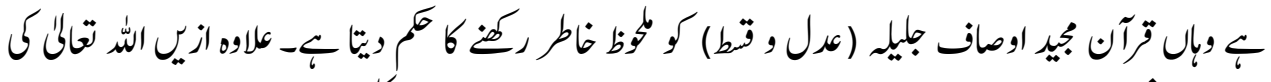

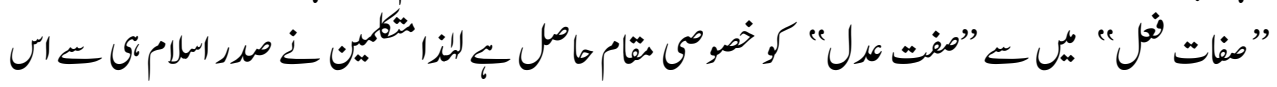

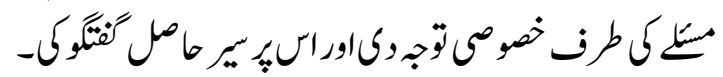

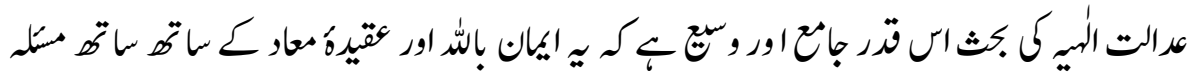

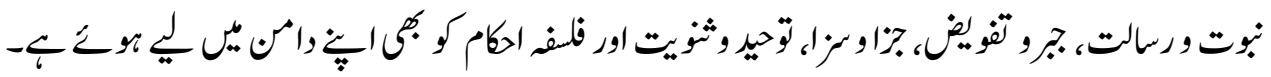

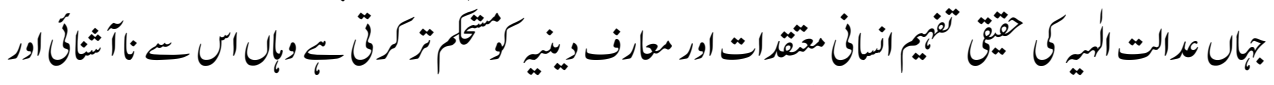

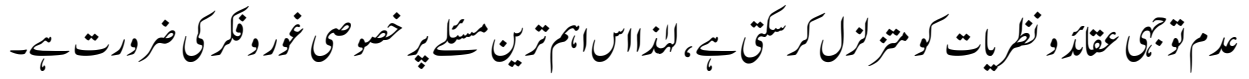

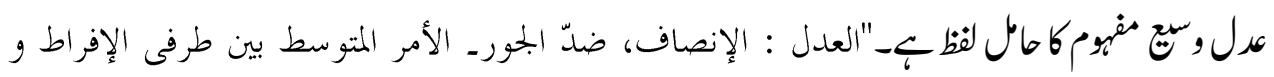

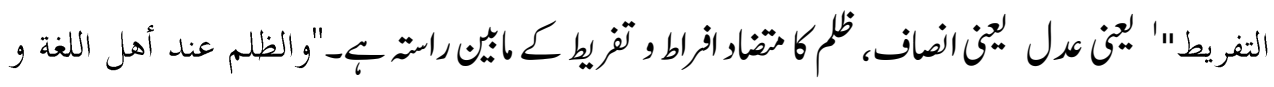

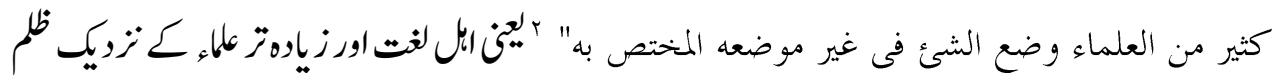

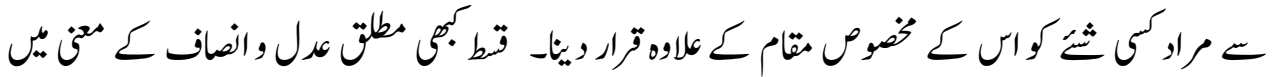

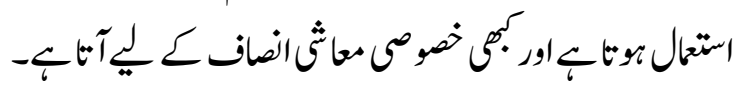

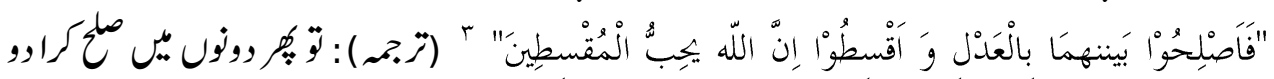

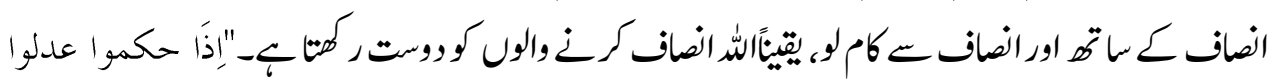

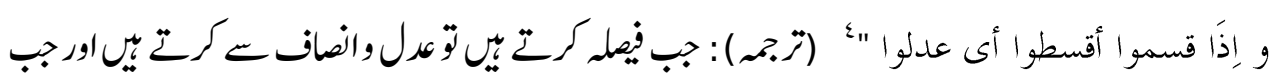

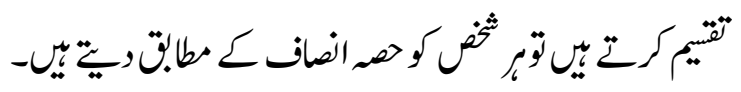

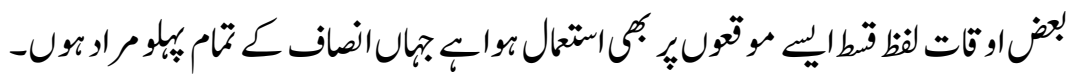

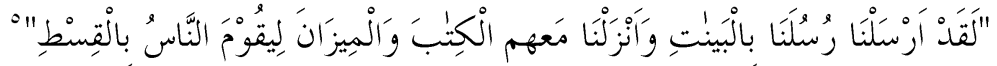

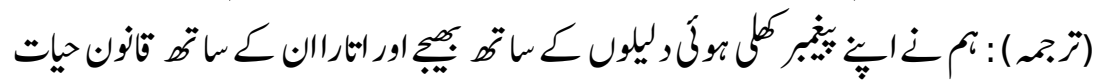

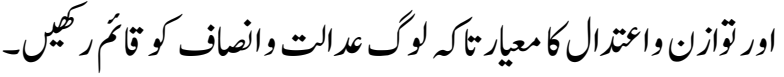

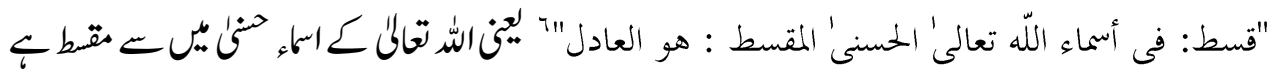

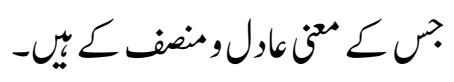




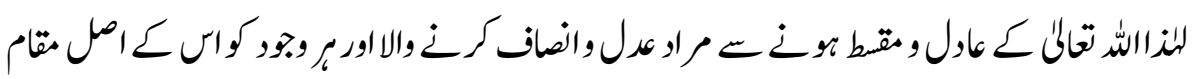

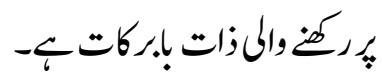

$$
\begin{aligned}
& \text { عرالتاليمكانميت }
\end{aligned}
$$

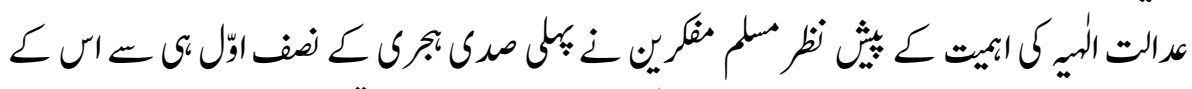

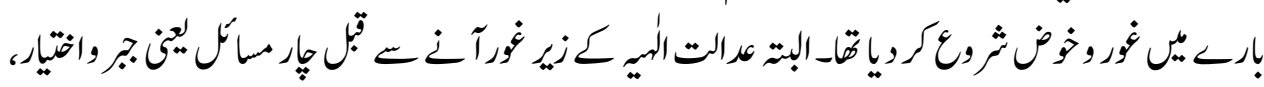

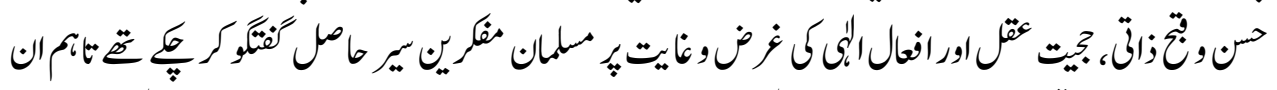

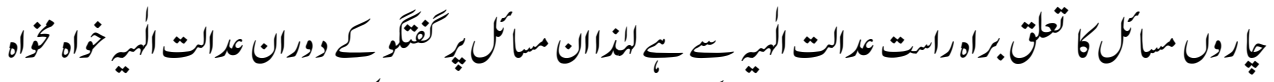

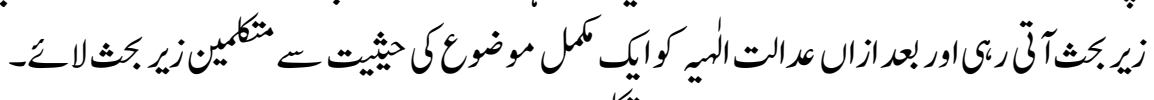

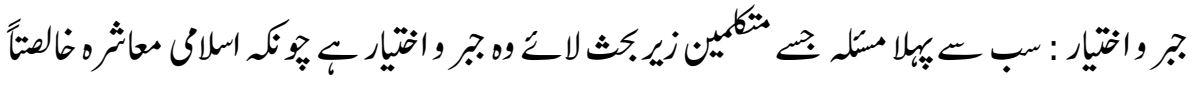

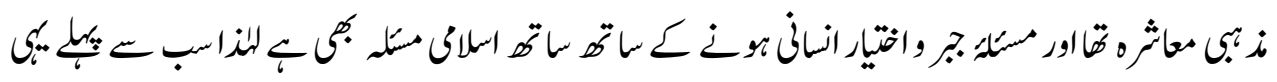

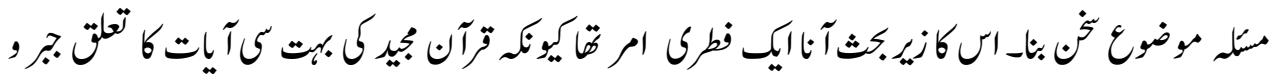

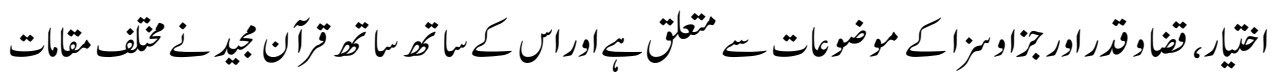

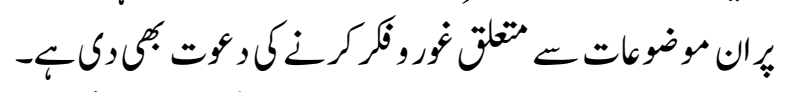

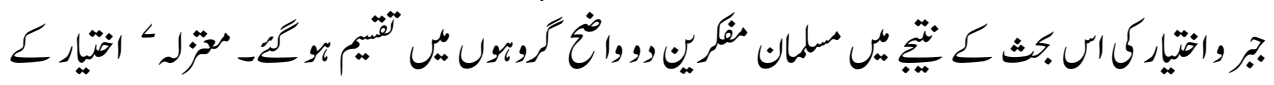

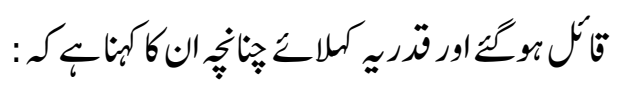

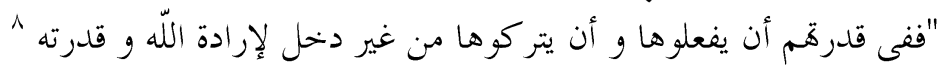

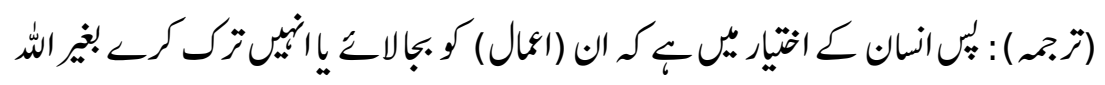

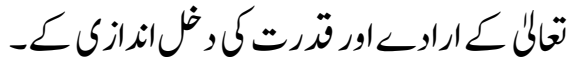

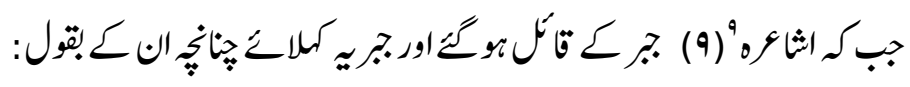

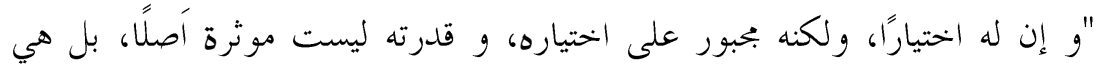

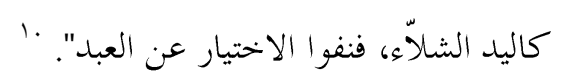

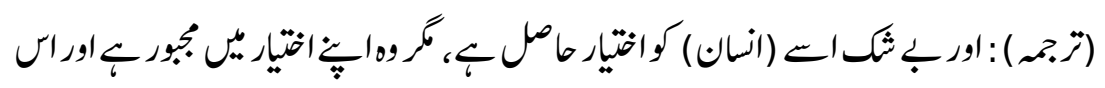

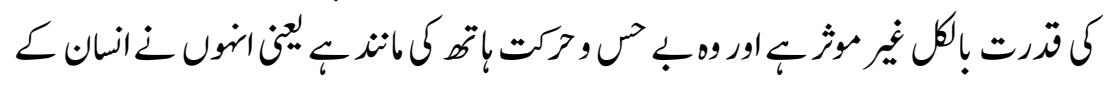

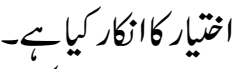

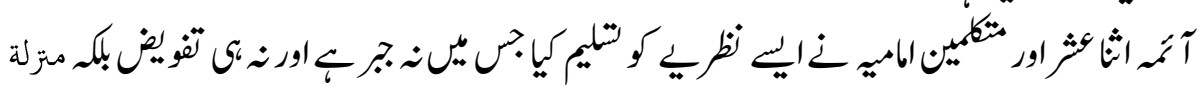




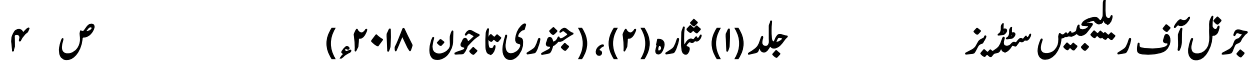

"عن أبى عبد الله عليه السلام قال : سئل عن الجبر والقدر فقال : لاجبر ولا قدر

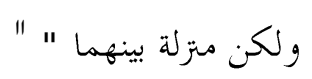

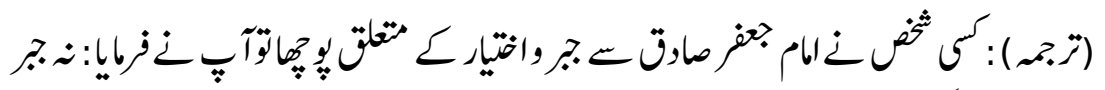

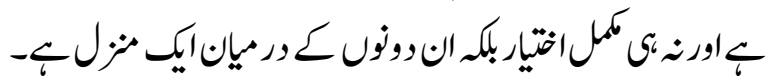

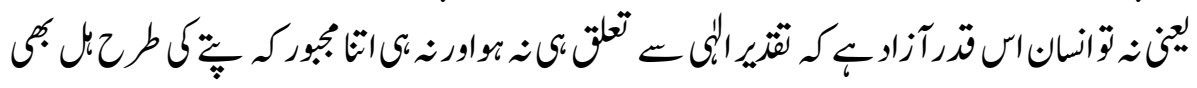

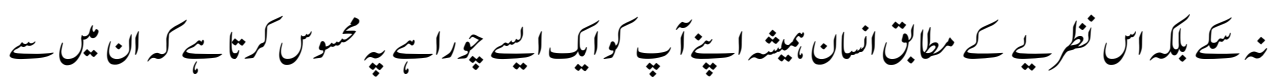

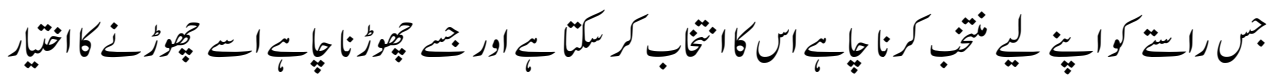

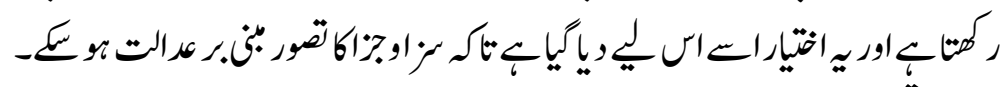

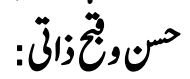

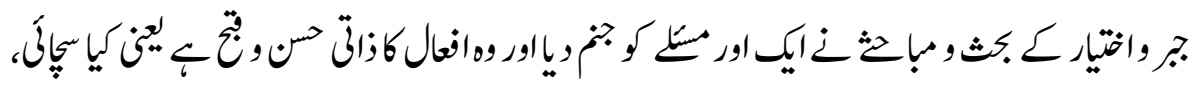

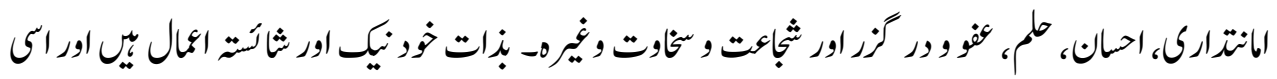

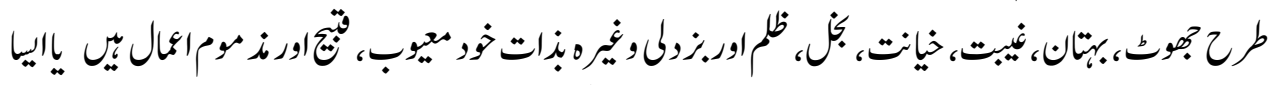

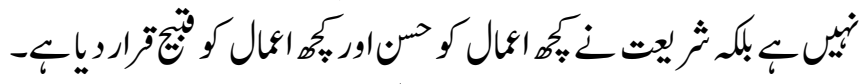

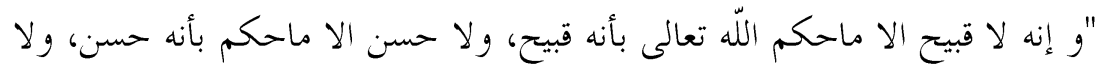

$$
\text { مزيد" }
$$

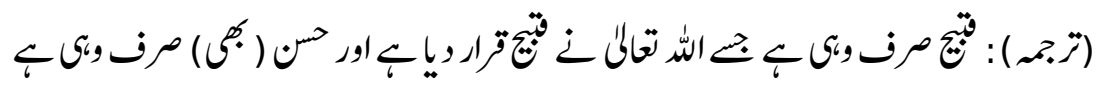

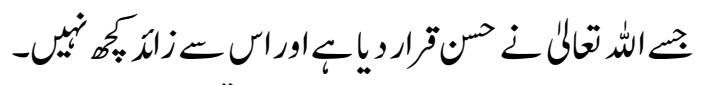

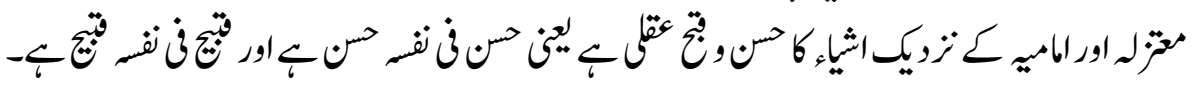

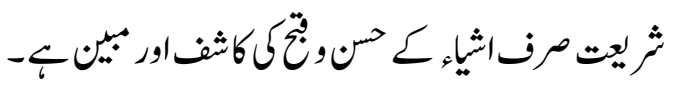

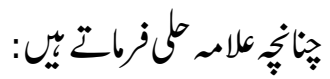

"قلنا ذلك لأنه تعالى غنيّ يستحيل عليه الحاجة و هو عالم بلمسن الحسن و قبح القبيح،

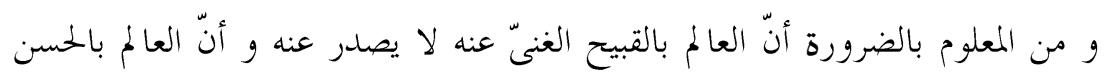
القادر عليه اذا خلا من جهات المفسدة فإنه يوجده، و تحريره أنّ الفعل بالنظر إلى ذاته

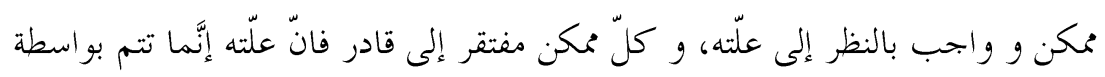

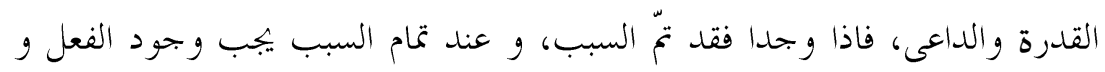
أيضًا لو جاز منه فعل القبيح أو الإخلال بالواجب لارتفع الوثوق بوعده و وعيده" 


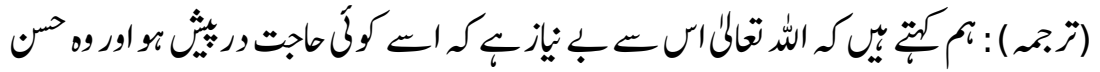

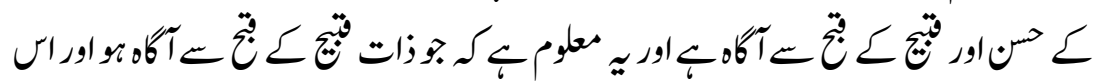

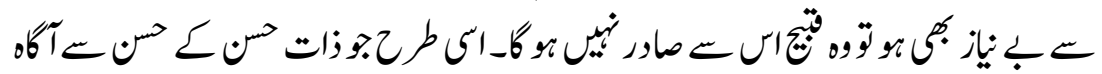

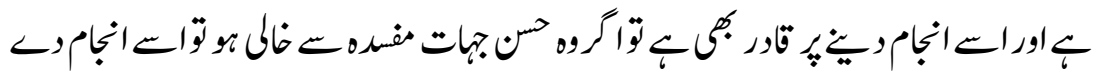

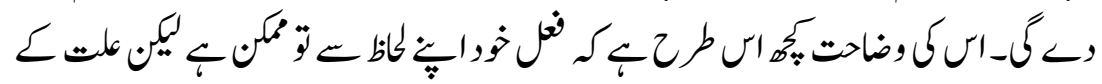

$$
\text { لحاظط واجب }
$$

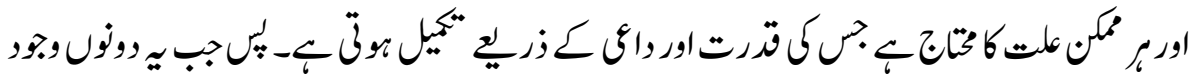

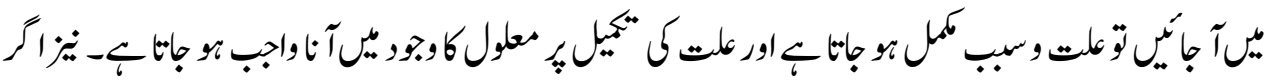

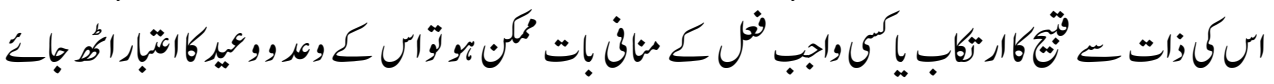

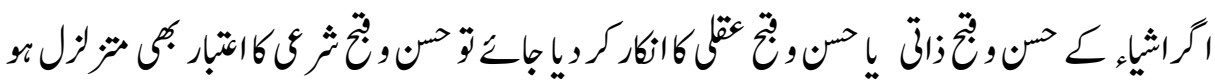

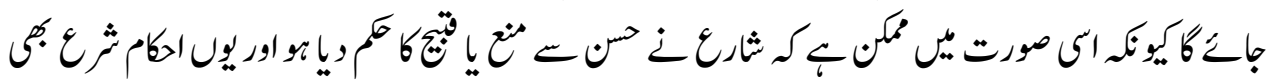

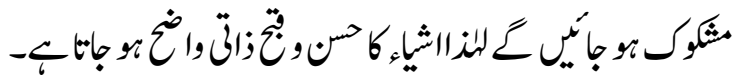

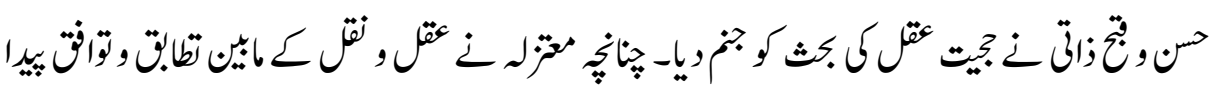

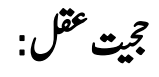

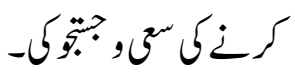

When the $M \bar{u}$ 'tāzilites came, they raised the status of aql (reason) almost making it equal to naql (tradition), as can be seen from statements of Wâsill, who said: "Truth can be known from four sources: the Qur'ān, agreed Hadi'th, rational argument, and ljmā. ${ }^{14}$

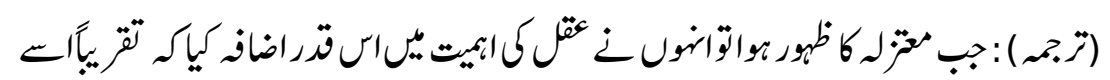

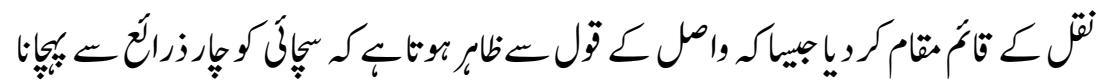

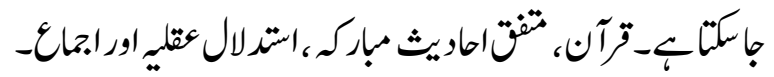

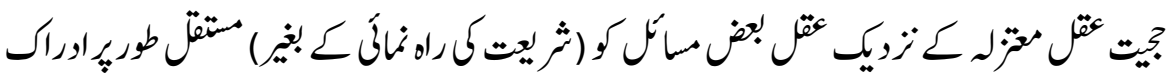

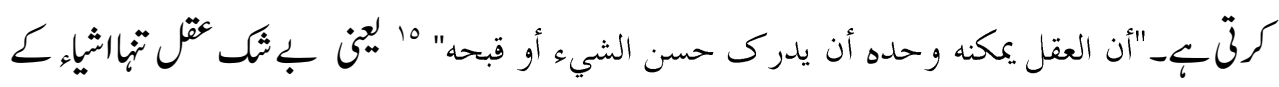

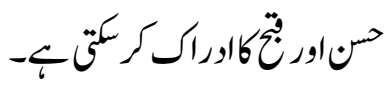




\section{جرثل آف ربيجيي سئيز}

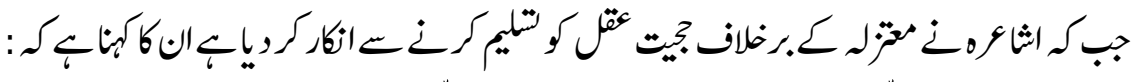

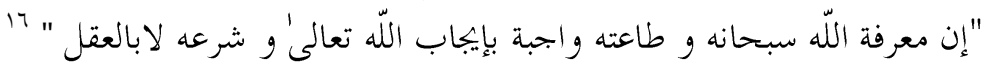

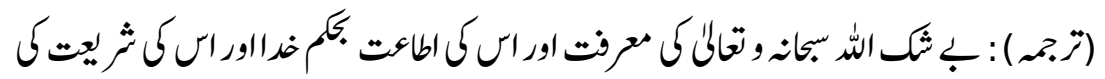

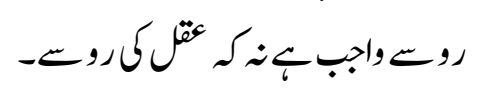

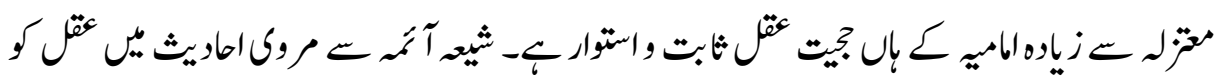

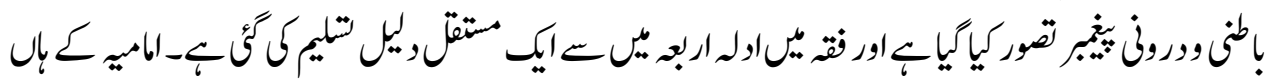

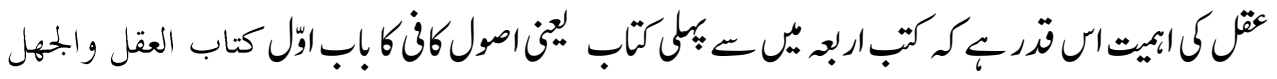

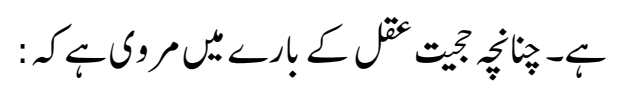

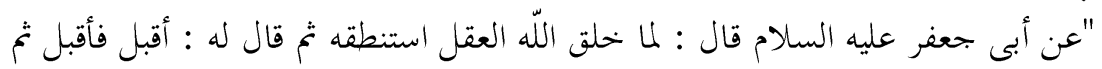

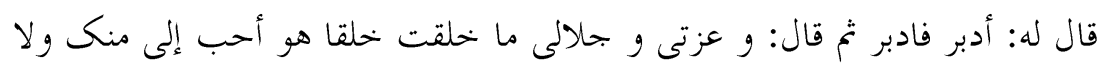

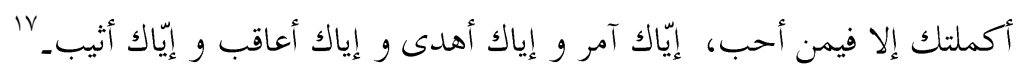

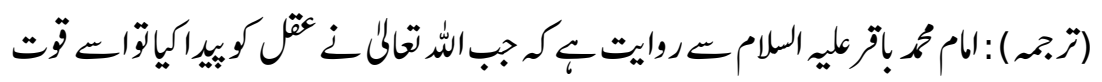

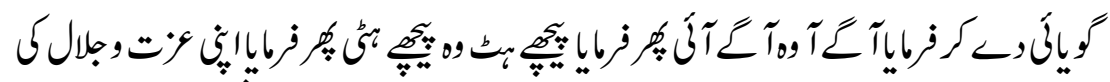

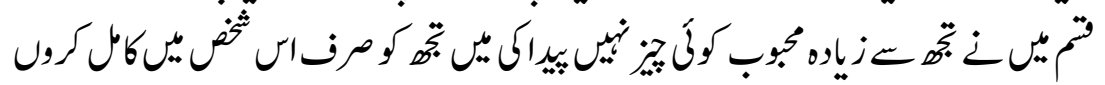

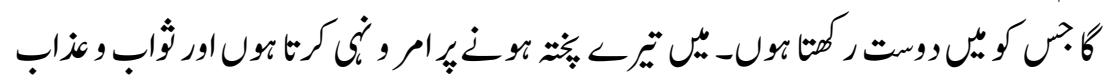
وبيتانون-

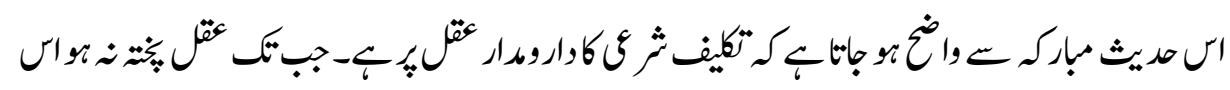

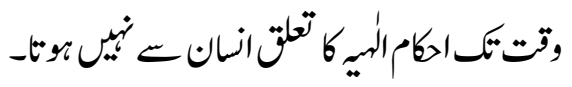

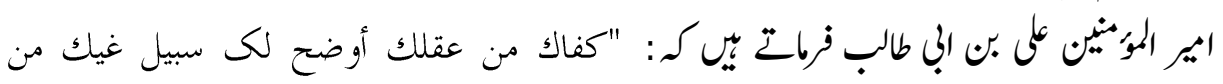

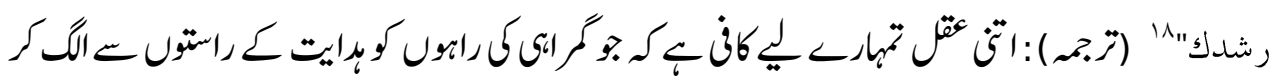

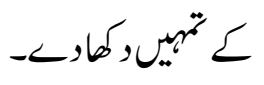

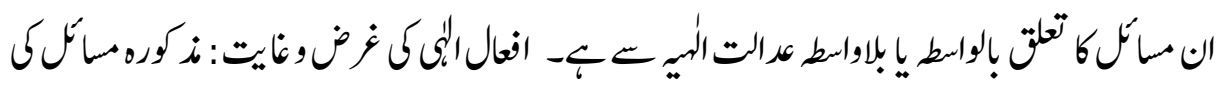

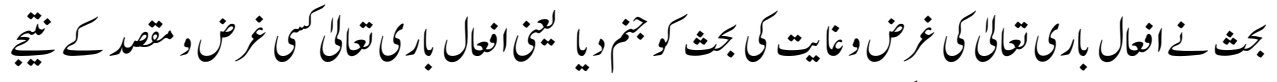

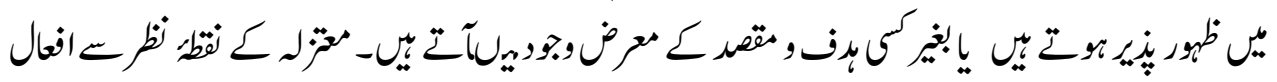

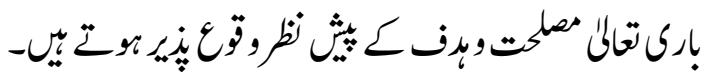

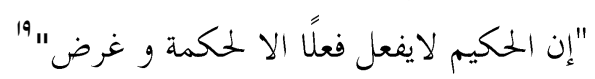

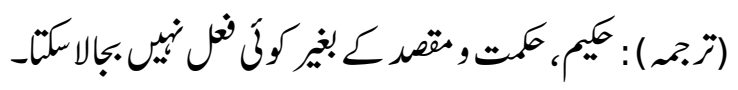




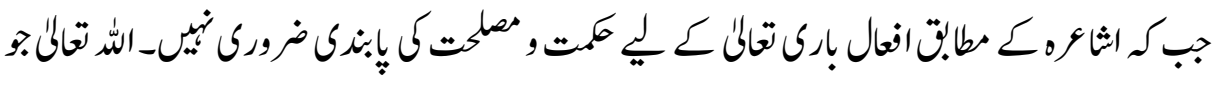

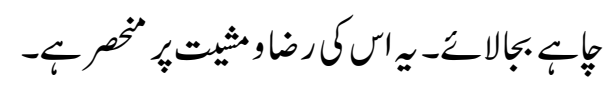

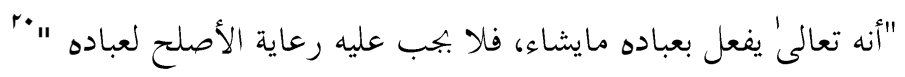

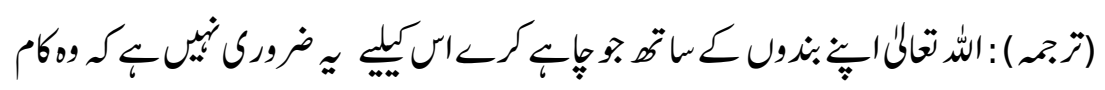

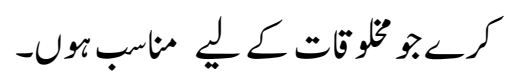

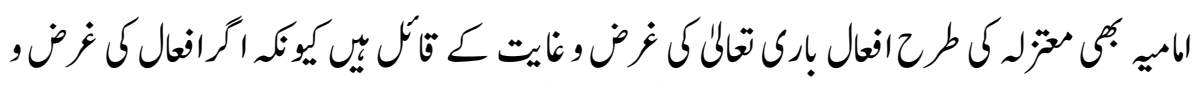

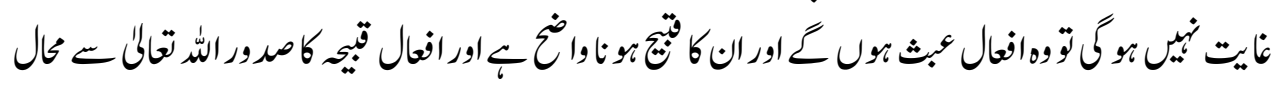

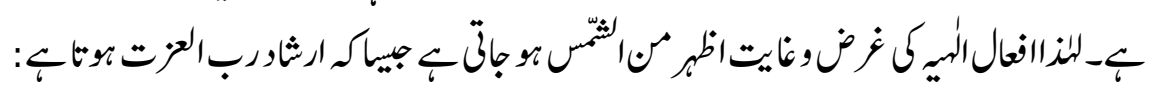

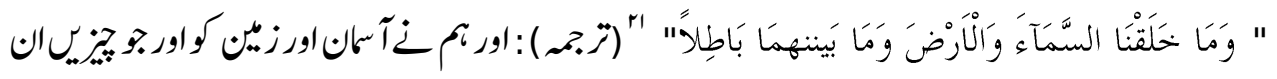

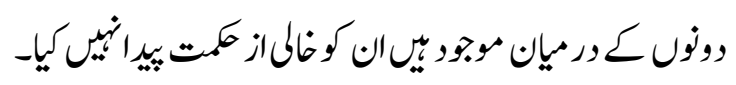

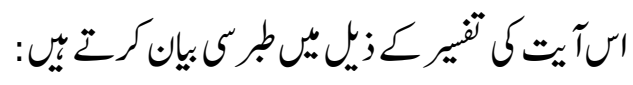
"خلقناهما لغرض حكمي وهو ما في ذلك من إظهار الحكمة.-.. وهذا ينافي قول قول أهل

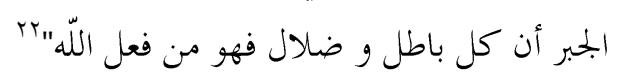

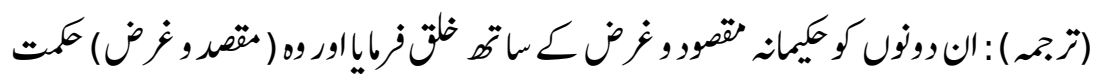

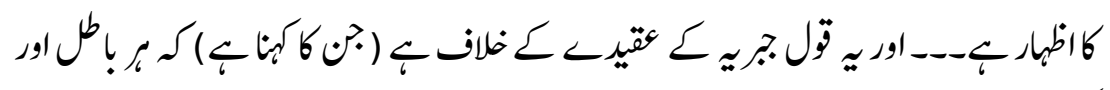

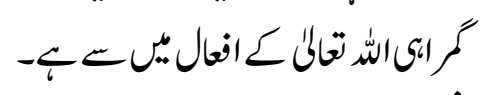

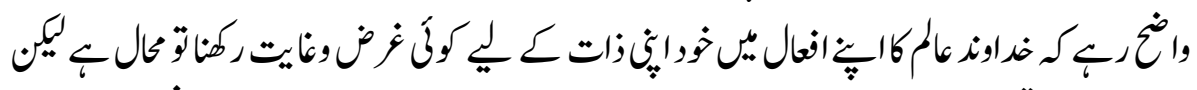

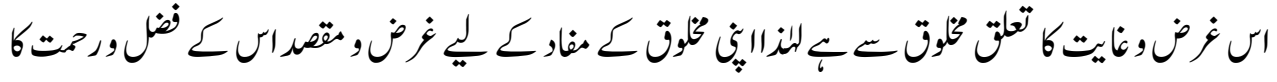

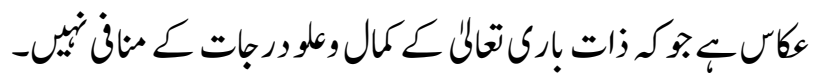

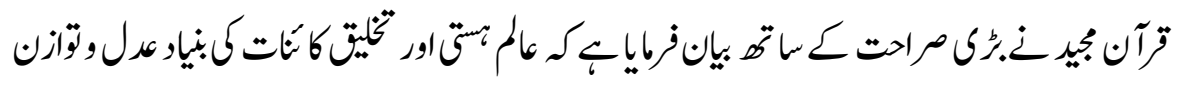

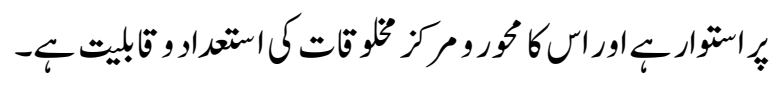

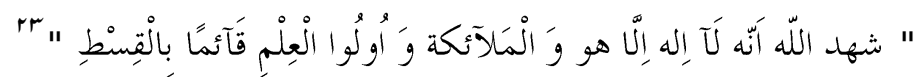

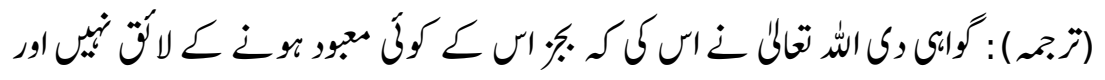

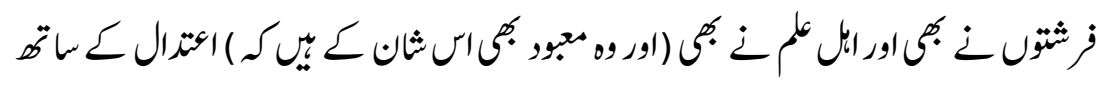

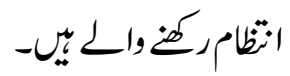

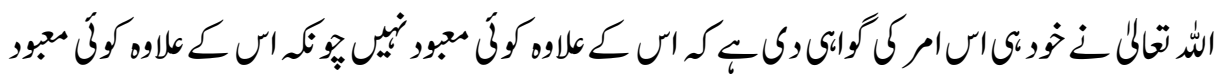

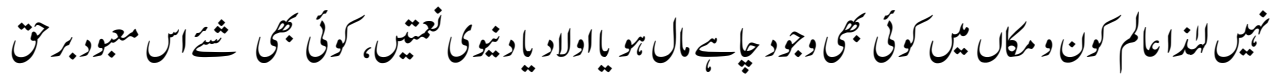




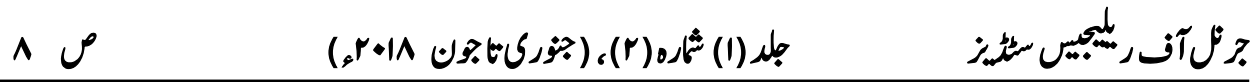

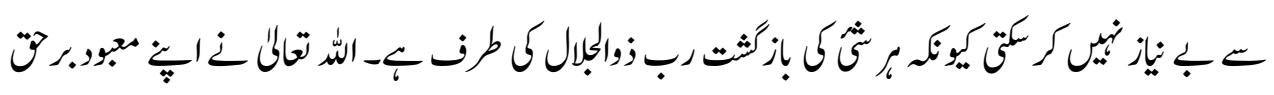

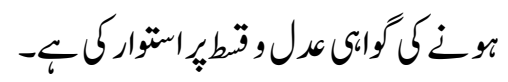

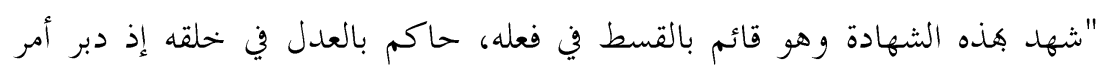

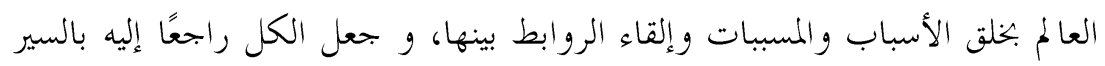

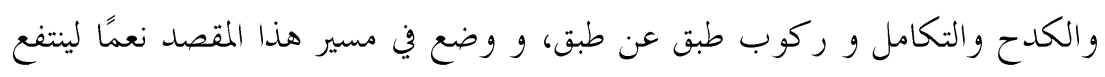

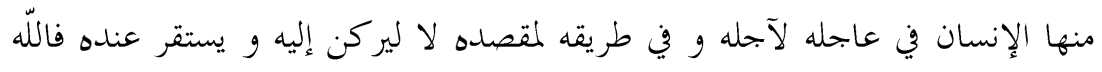
يشهد بذلك وهو شاهد عدل"

قط وعدل

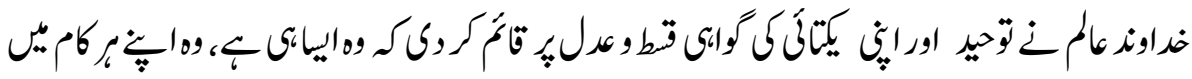

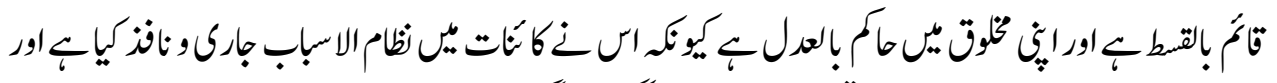

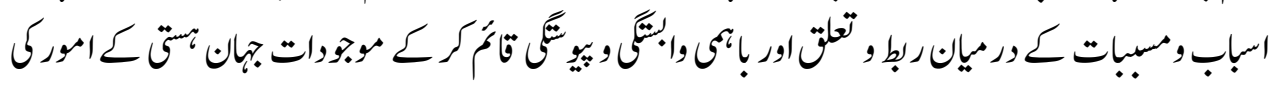

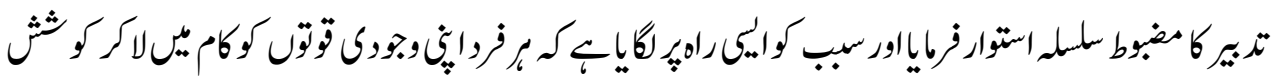

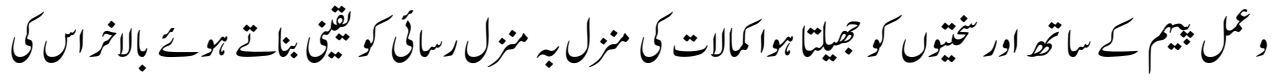

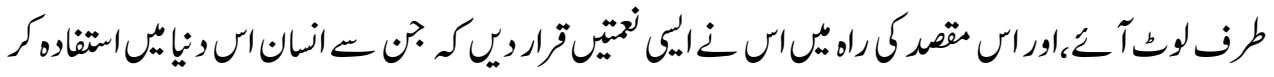

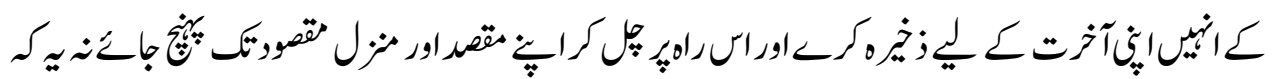

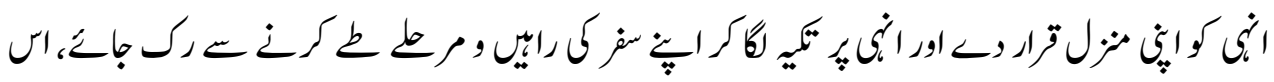

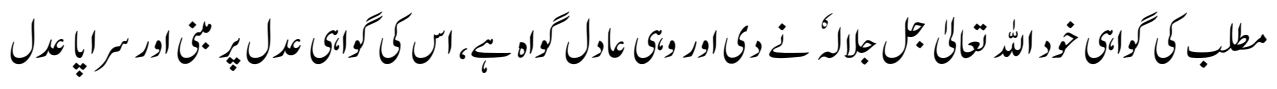

$-6$

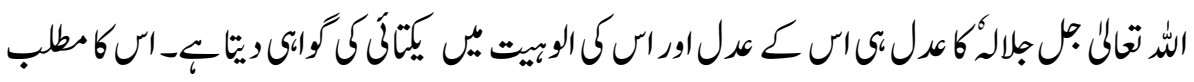

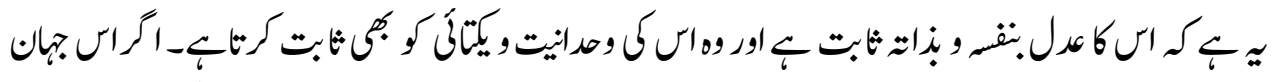

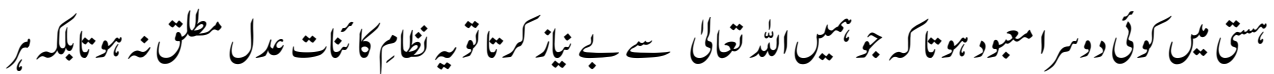

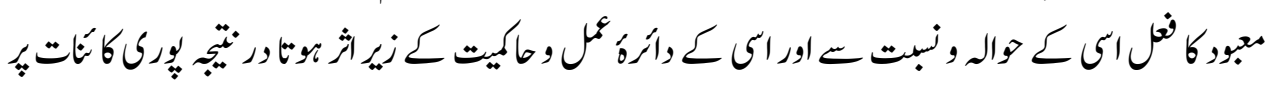

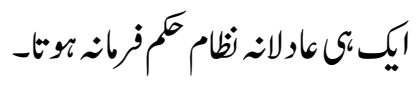

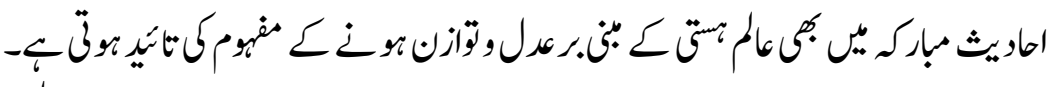

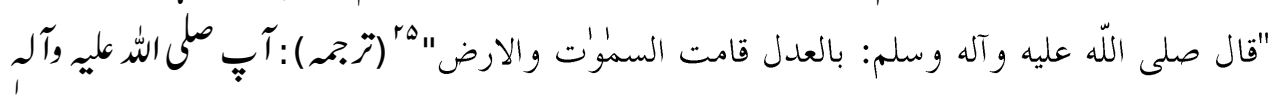

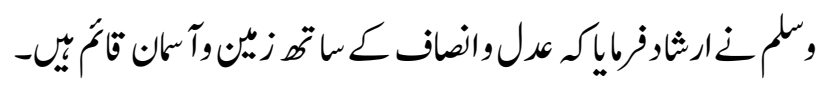




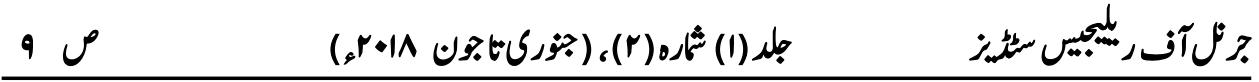

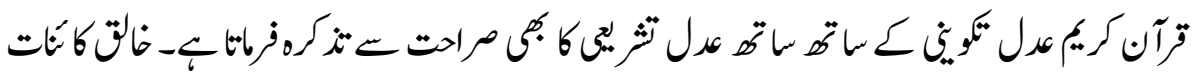

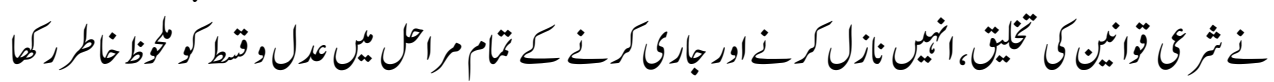

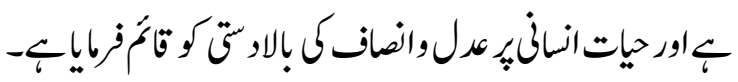

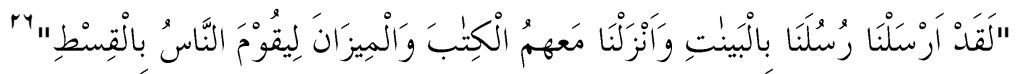

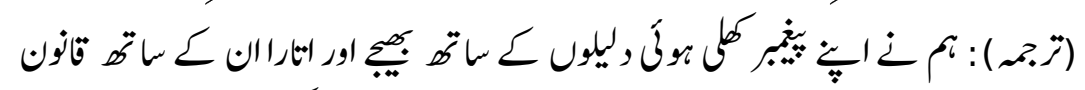

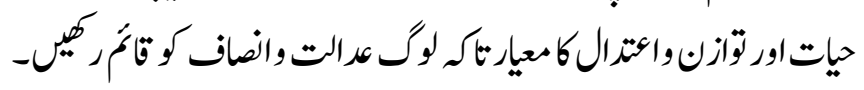

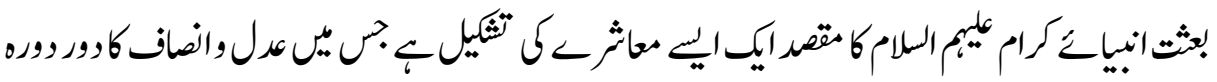

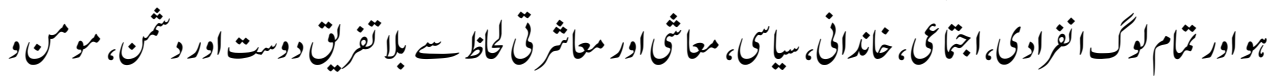

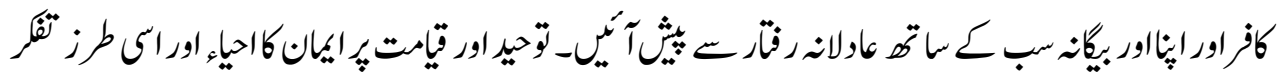

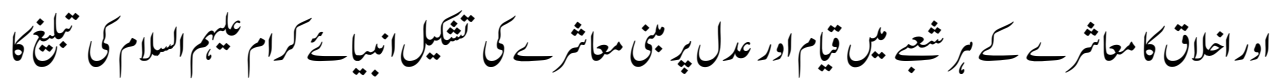

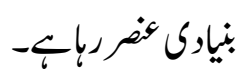

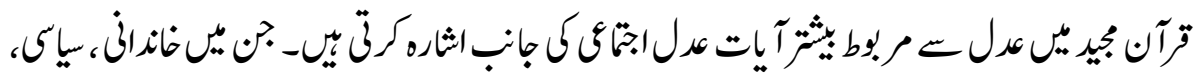

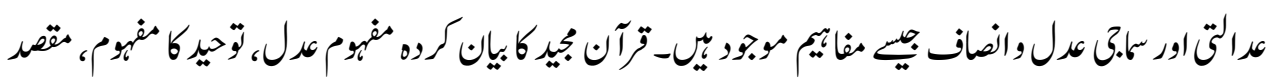

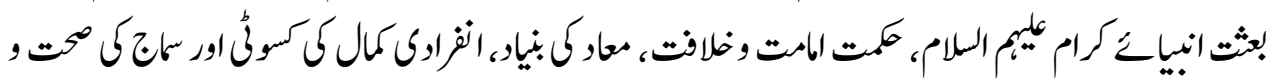

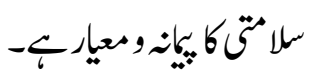

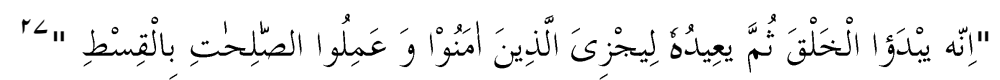

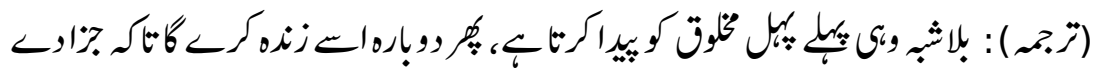

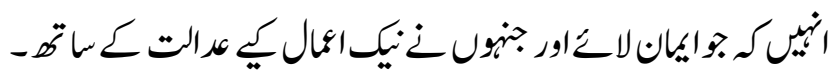

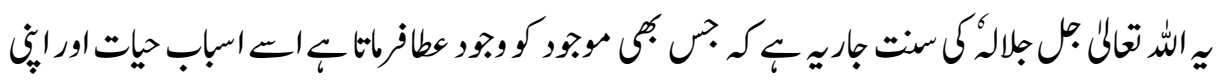

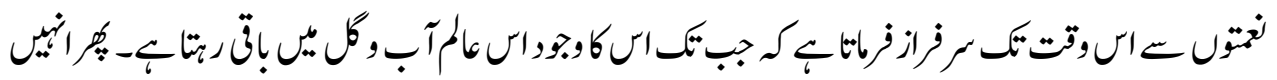

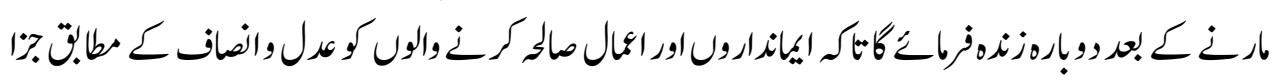

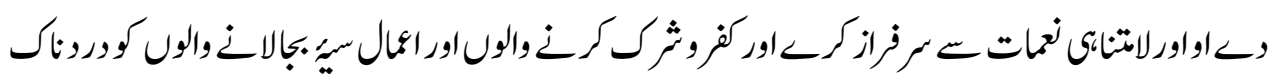

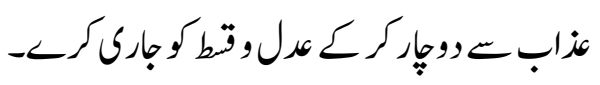

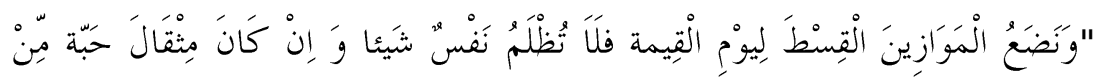

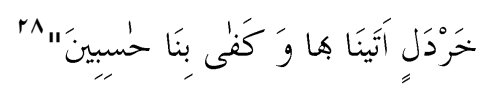




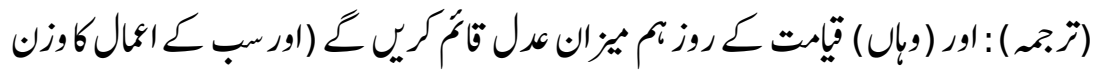

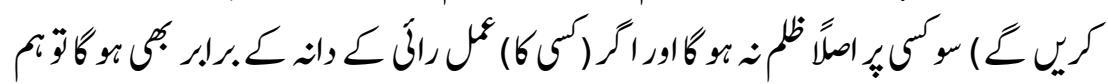

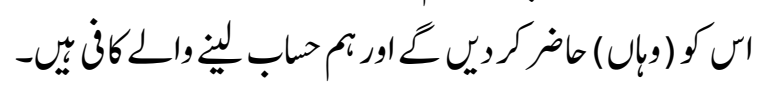

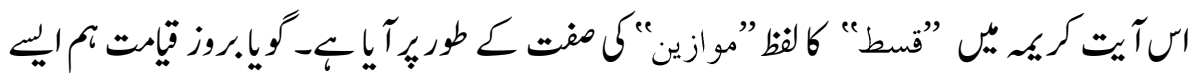

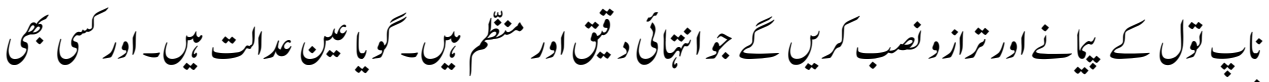

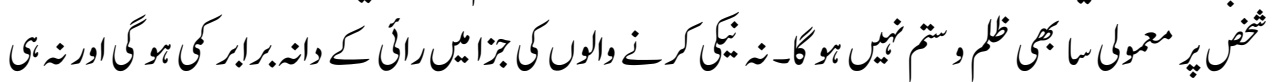

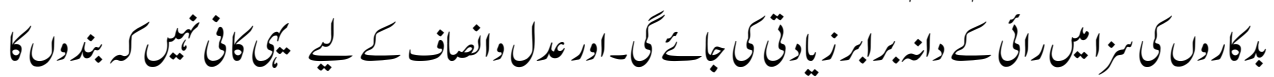

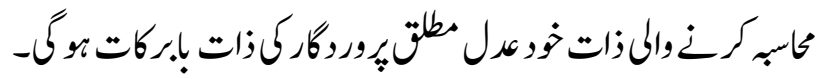

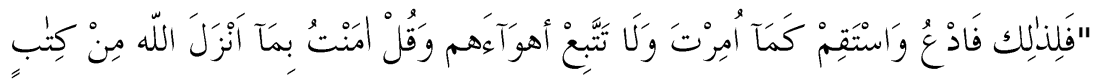

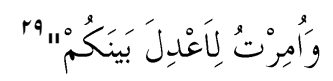

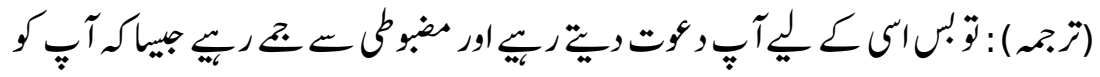

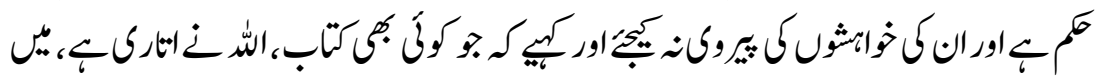

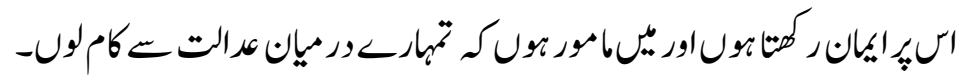

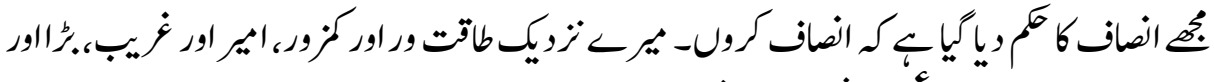

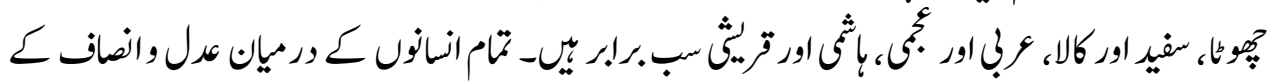

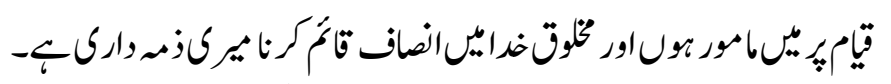

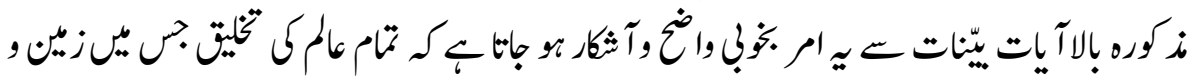

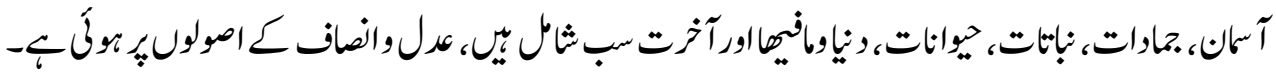

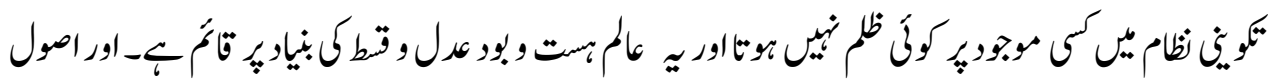

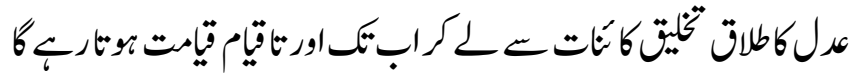
كيونك

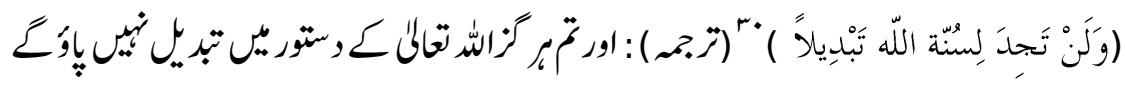

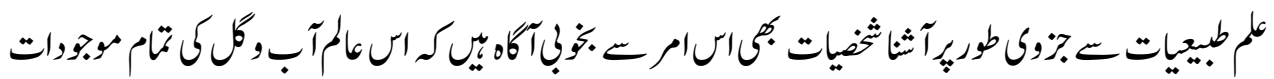

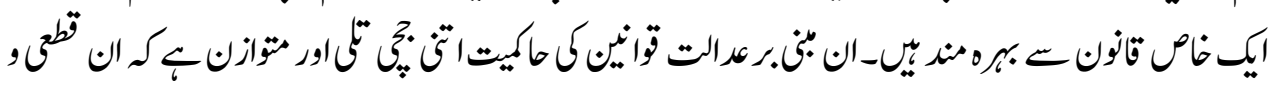

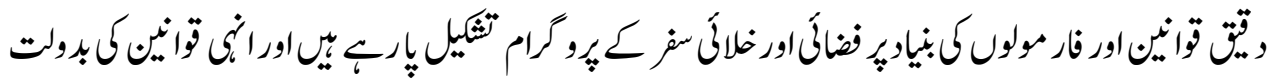

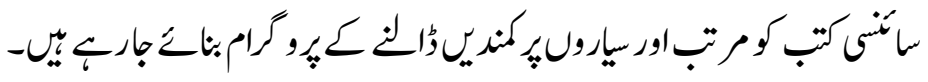




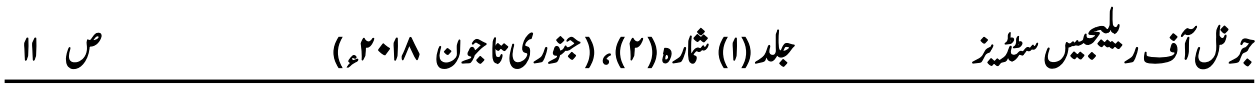

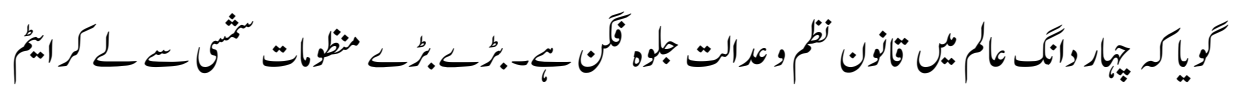

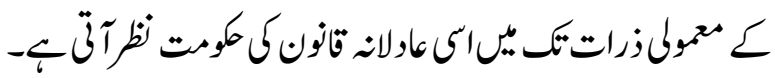

تمأُكث

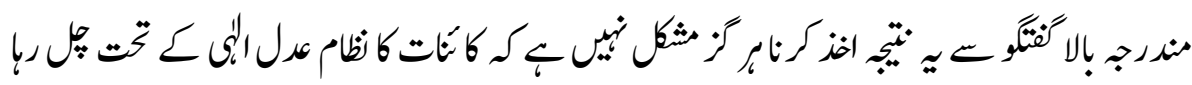

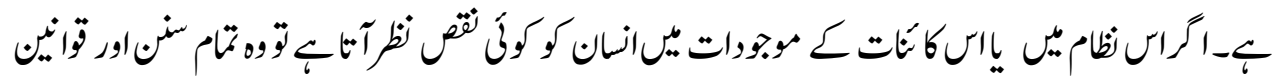

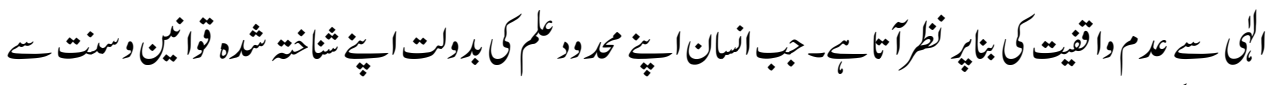

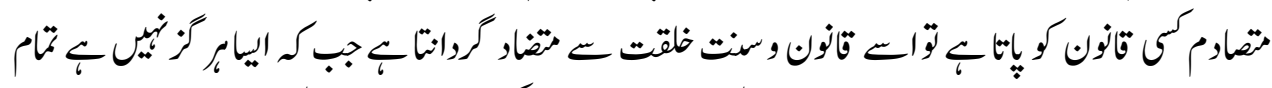

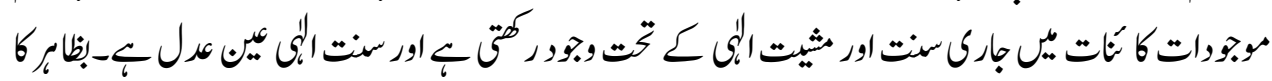

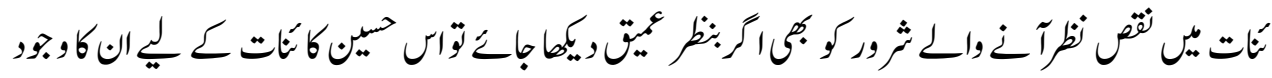

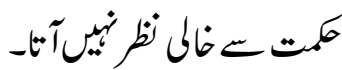

קر

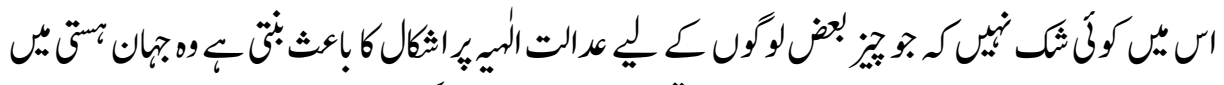

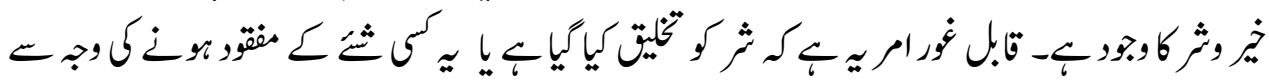

ن

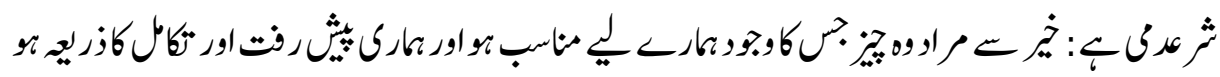

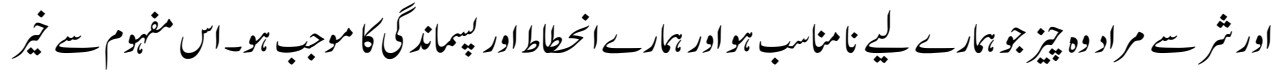

,

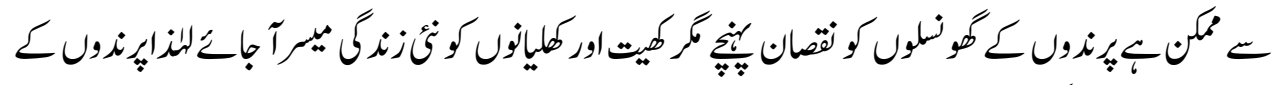

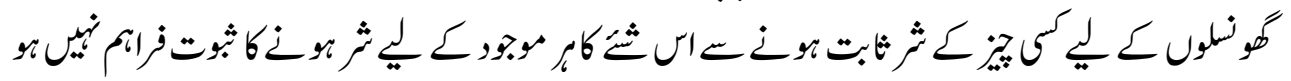

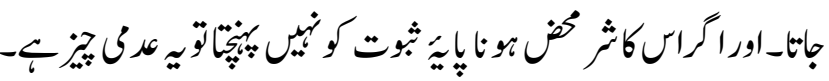

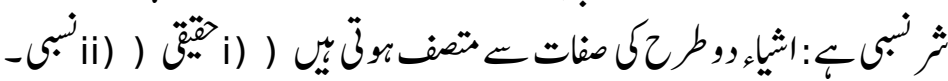

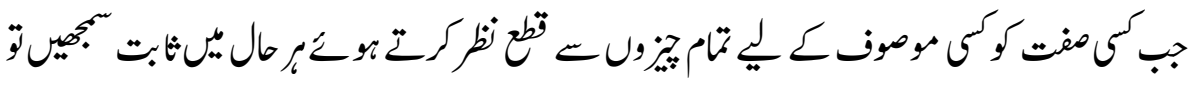

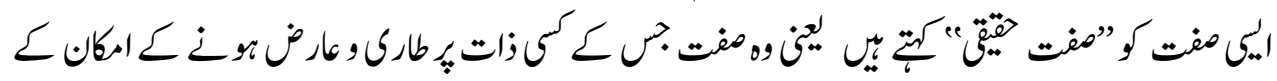

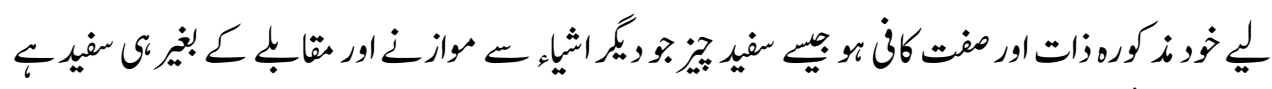

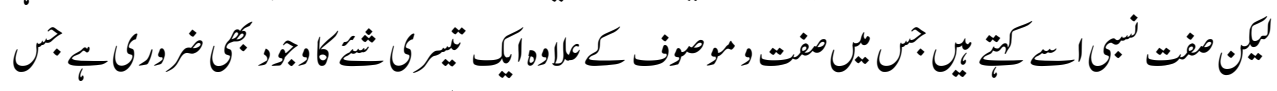

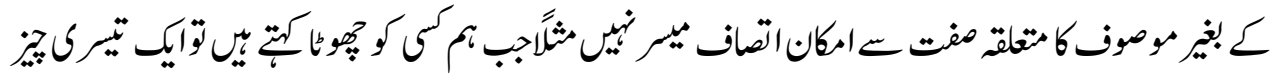




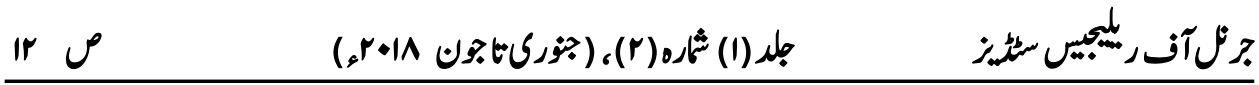

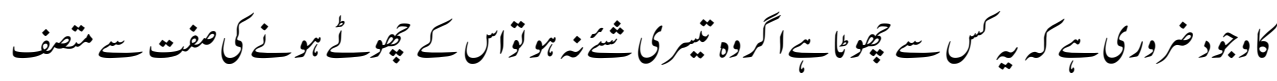

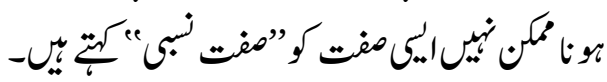

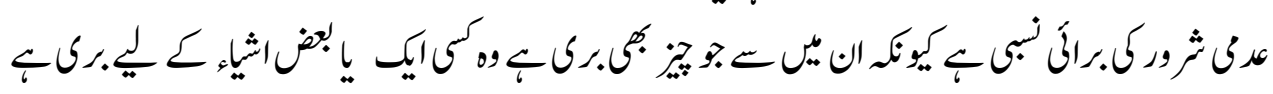

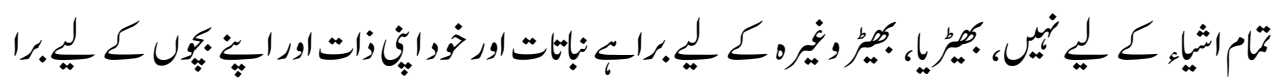

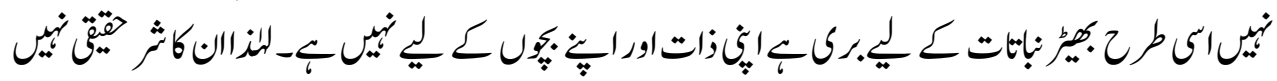

ب.

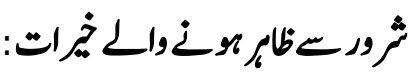

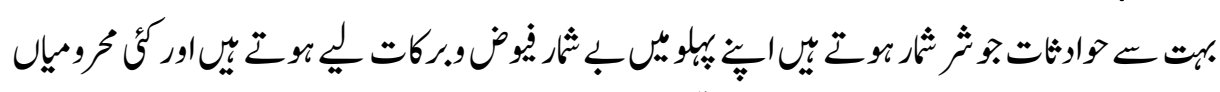

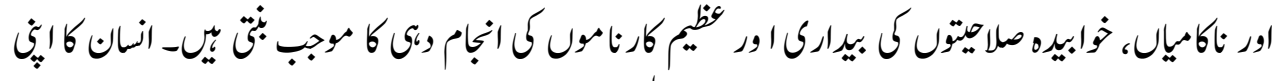

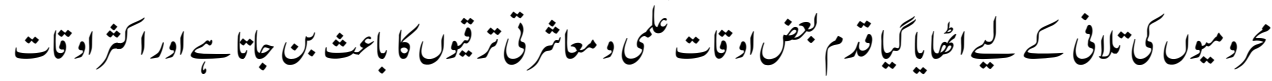
كt

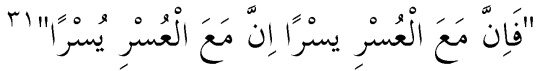

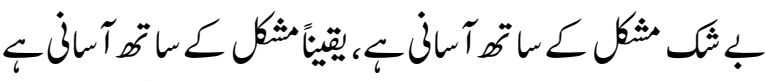

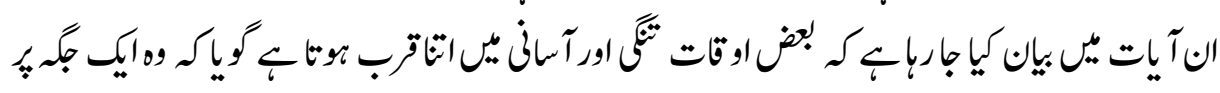

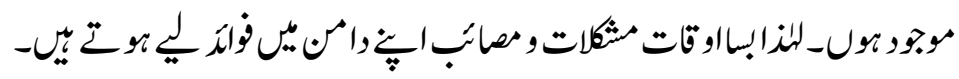
1

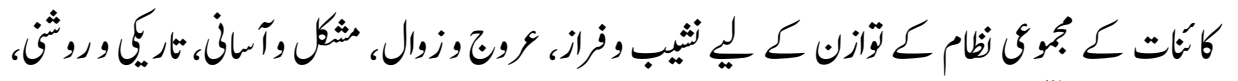

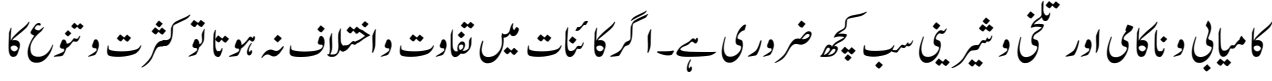

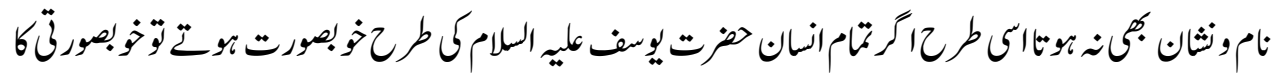

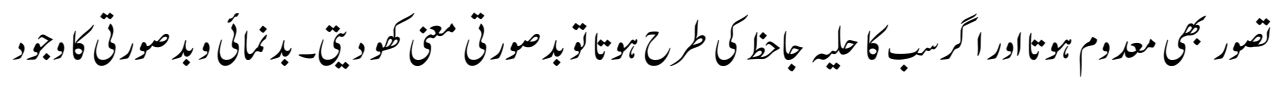

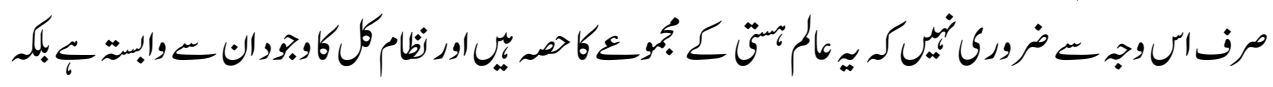

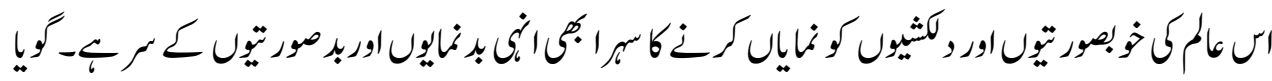

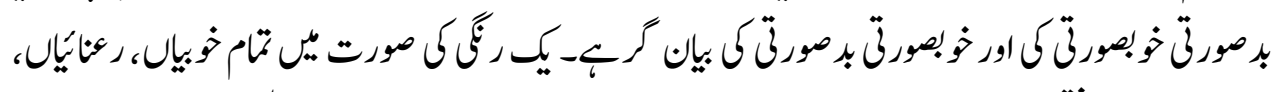

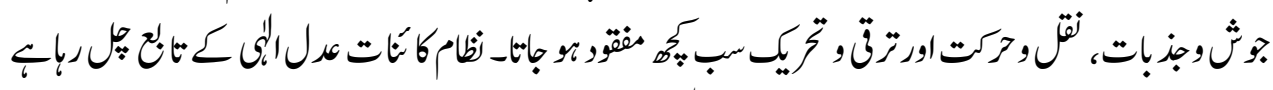

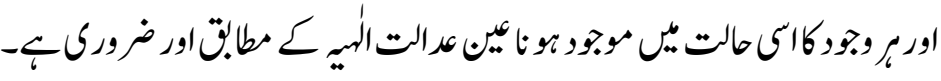

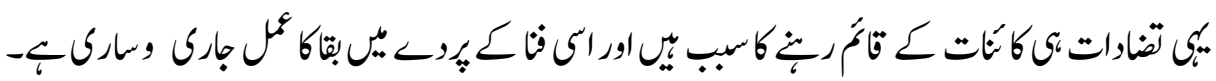

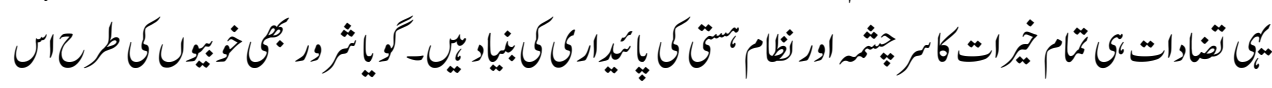




\section{جزل آفربيجيي سئديز}

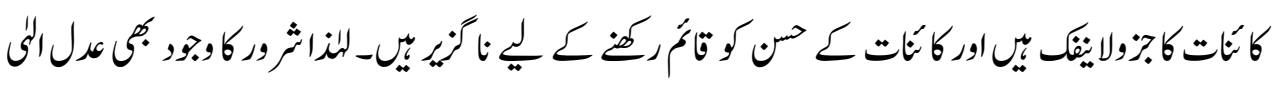

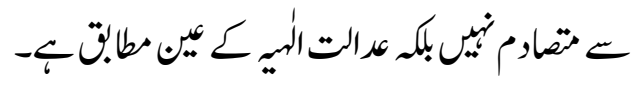

\section{واثى ووال بات}

الجر، الدكتور الخليل، لاروس المعتم العربى الحديث، مكتبة لاروس، لا شارع مونيارناس، باريس

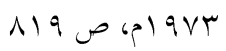

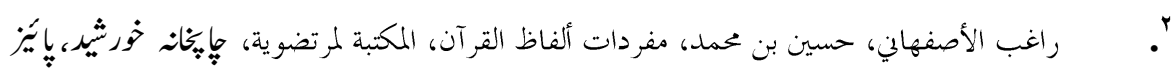

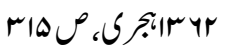

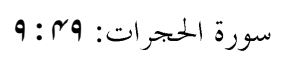

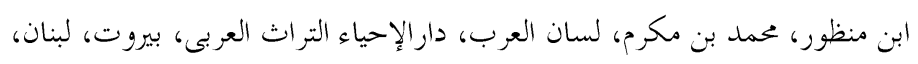

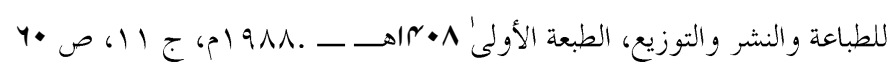

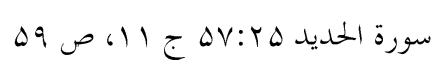

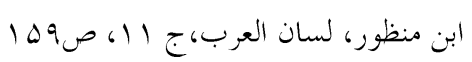

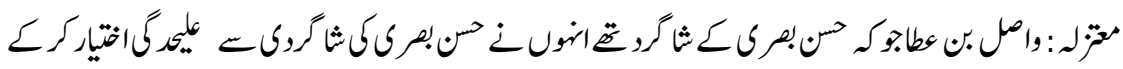

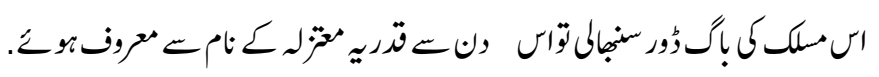

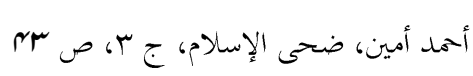

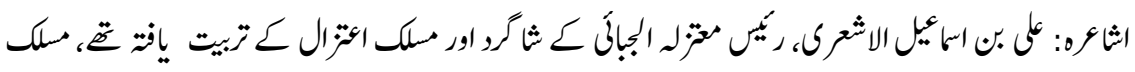

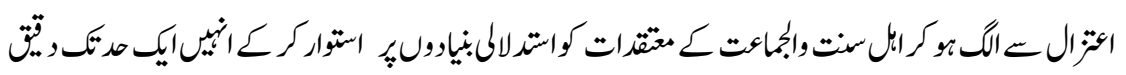

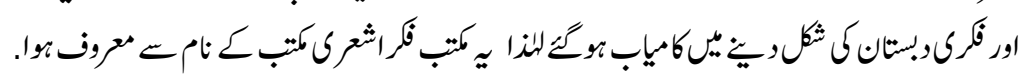

أمهد أمين، ظهر الإسلام، منشور ات محمد على بيضون، دار الكتب العلمية، بيروت،

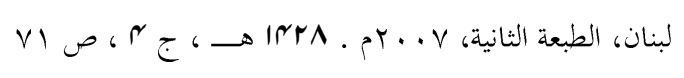

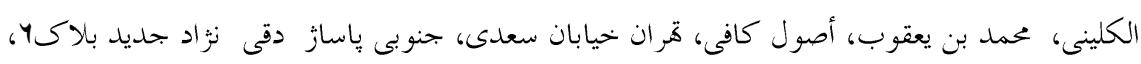

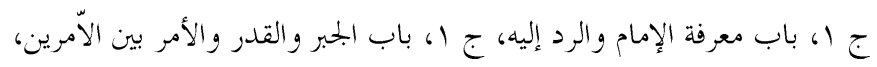

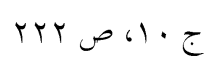

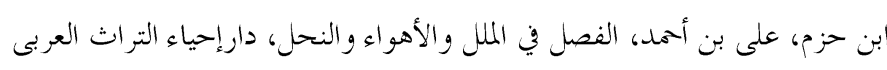

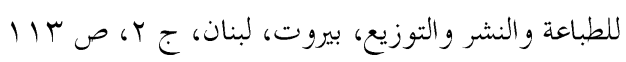

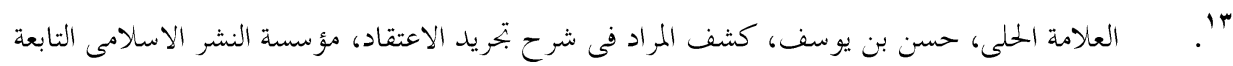

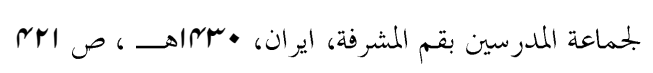

Nasr, Encyclopedia of Islamic Philosophy, Part1, p. 81 


$$
\begin{aligned}
& \text { ". }
\end{aligned}
$$

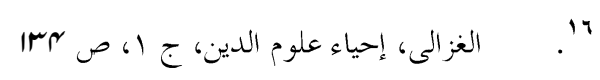

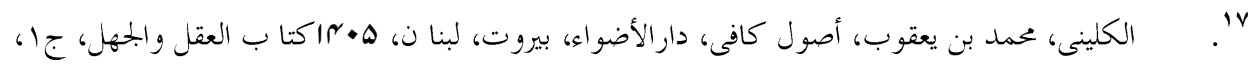

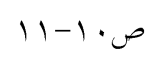

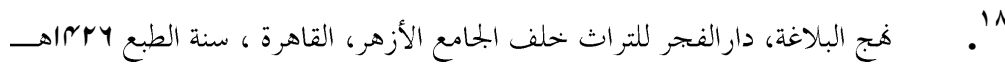

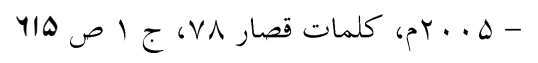

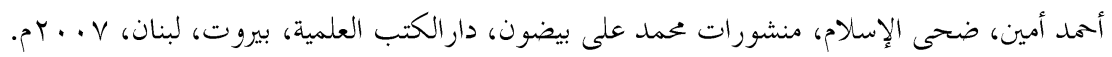

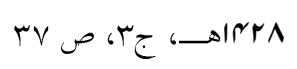

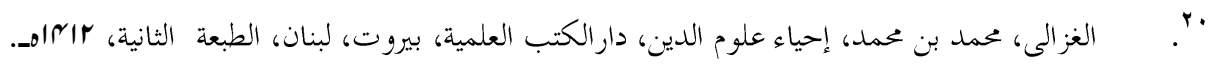

$$
\begin{aligned}
& \text { }
\end{aligned}
$$

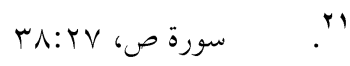

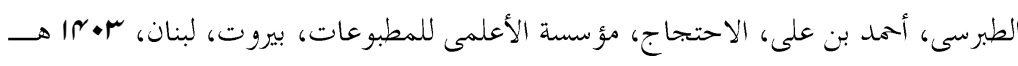

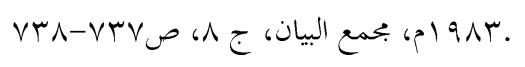

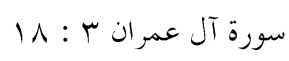

الطباطبائى، علامة محمد حسين، الميزان ، منشورات مؤسسة الأعلمى للمطبوعات، بيروت، لبنان، الطبعة

$$
\begin{aligned}
& \text { الثالثة rq ب إ هـ. }
\end{aligned}
$$

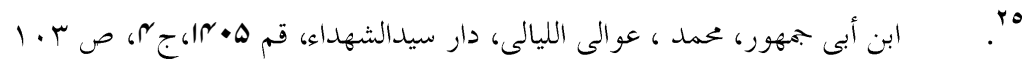

$$
\begin{aligned}
& \text { ro: }
\end{aligned}
$$

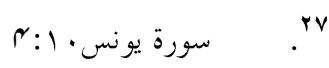

$$
\begin{aligned}
& r \begin{aligned}
r \\
r
\end{aligned} \\
& \text { a } \\
& \text {. }
\end{aligned}
$$

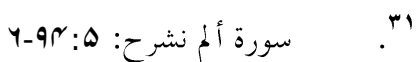

@ 2017 by the author, Licensee University of Chitral, Journal of Religious Studies. This article is an open access article distributed under the terms and conditions of the Creative Commons Attribution (CC BY) (http://creativecommons.org/licenses/by/4.0/). 